\title{
A Concise Introduction to Calculus
}




\title{
SERIES ON UNIVERSITY MATHEMATICS
}

\author{
Editors: \\ WY Hsiang : Department of Mathematics, University of California, Berkeley, \\ CA 94720 , USA \\ T T Moh : Department of Mathematics, Purdue University, W. Lafayette \\ IN 47907, USA \\ e-mail: ttm@ @math.purdue.edu Fax: 317-494-6318 \\ S S Ding : Department of Mathematics, Peking University, Beijing, China \\ M C Kang : Department of Mathematics, National Taiwan University, \\ Taiwan, China \\ M Miyanishi : Department of Mathematics, Osaka University, Toyonaka, \\ Osaka 560, Japan
}

Published
Vol. 5: Algebra
TTMoh

Forthcoming

Vol. 1: Differential Geometry S S Chern

Vol. 2: Lie Group

WY Hsiang

Vol. 3: Classical Geometries

WY Hsiang

Vol. 4: Foundation of Linear Algebra

W Y Hsiang \& T T Moh

Vol. 7: Number Theory with Applications

$W-C$ Winnie $L i$ 


\section{SERIES ON UNIVERSity Mathematics Vol. 6}

\section{A CONCISE INTRODUCTION TO}

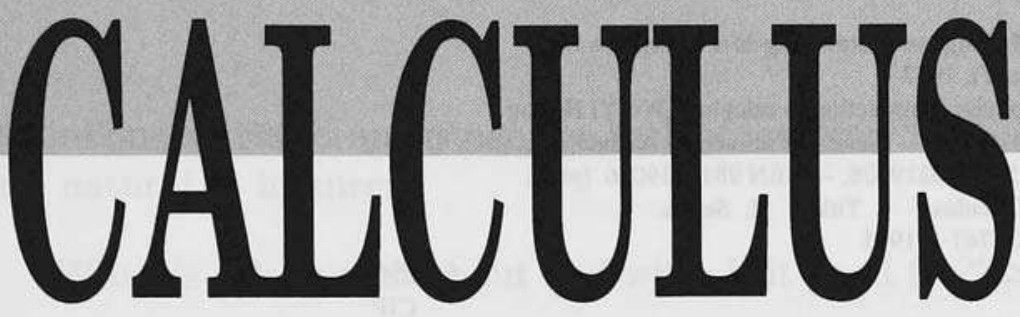

\section{W Y Hsiang \\ Department of Mathematics \\ University of California \\ Berkeley, USA}


Published by

World Scientific Publishing Co. Pte. Ltd.

P O Box 128, Farrer Road, Singapore 9128

USA office: Suite 1B, 1060 Main Street, River Edge, NJ 07661

UK office: 57 Shelton Street, Covent Garden, London WC2H 9HE

\section{Library of Congress Cataloging-in-Publication Data \\ Hsiang, Wu Yi, 1937-}

A concise introduction to calculus / Wu-Yi Hsiang.

p. $\quad \mathrm{cm}$. - (Series on university mathematics; vol. 6)

ISBN 9810219008 . - ISBN 9810219016 (pbk.)

1. Calculus. I. Title. II. Series.

QA303.H747 1995

515--dc20

95-15402

CIP

\section{British Library Cataloguing-in-Publication Data}

A catalogue record for this book is available from the British Library.

Copyright $\odot 1995$ by World Scientific Publishing Co. Pte. Ltd.

All rights reserved. This book, or parts thereof, may not be reproduced in any form or by any means, electronic or mechanical, including photocopying, recording or any information storage and retrieval system now known or to be invented, without written permission from the Publisher.

For photocopying of material in this volume, please pay a copying fee through the Copyright Clearance Center, Inc., 222 Rosewood Drive, Danvers, Massachusetts 01923, USA 


\section{Introduction}

Before one starts to undertake the task of learning "calculus", it is rather natural to inquire:

\section{"What is calculus all about and what is it good for?"}

We believe that a beginner is entitled to get an outright answer of such basic questions, if possible, at the outset.

Let us begin by observing that we are living in an ever-changing universe full of all kinds of dynamic phenomena and systems with variable quantities. For example, although we don't quite feel the motion, the earth is, in fact, spinning daily and rotating around the sun yearly; the so-called "law of gases" states the definitive correlation between the volume, the pressure and the temperature of a given amount of gas; the so-called "laws of trigonometry" provides a set of interlocking fundamental relationships among the three angles and the three sides of an arbitrary triangle. The changing of weather and the behavior of economy are still rather difficult to predict because such systems consist of too many variable parameters and the interlocking correlations among so many variables are far from being reasonably understood (or even adequately grasped). Anyway, one definitely needs a type of mathematics which provides the general framework and basic tools for quantitative analysis of correlations among variable quantities. This is exactly what calculus is all about and what calculus is good for! In short, calculus is the basic setting and fundamental theory of the mathematics of variable quantities which provides the basic tools and the general framework for analyzing all kinds of correlations among variable quantities. Here, someone may wonder: 
Why not just call it "mathematics of variable quantities" rather than such a peculiar name "calculus"? Of course, there are more substantial questions about calculus other than the above question on its name. For example:

(i) What are the origin and intuitive source of calculus?

(ii) What are the basic concepts and the fundamental methodology of calculus?

(iii) What are the general framework and the basic structure of calculus?

(iv) What are the foundational theory and the typical applications of calculus?

The purpose of this concise introduction to calculus is to provide matter-of-fact, straight answers to the above set of basic questions about calculus, thus providing a good beginning for beginners in their journey of learning calculus. 


\section{Contents}

\section{Introduction}

Chapter 1: Numbers, Variables and Functions

$\S 1$. Real Numbers and Measurement

$\S 2$. Variables and Functions 20

Chapter 2: Basic Properties of Functions

$\S 1$. Monotonicity and Continuity of Functions

$\S 2$. Rate of Change and Sum of Total Effect of Functions

Chapter 3: Approximation and Limit

$\S 1$. Approximation and Limit of Sequences 48

$\S 2$. Limit and the Continuity of a Function 58

$\S 3$. Approximation and Integration of Piecewise Monotonic Functions

$\S 4$. Approximation and Differentiation of Piecewise Smooth Function

Chapter 4: Foundational Framework and

Fundamental Theory of Calculus

$\S 1$. The Foundation of Calculus

$\S 2$. Fundamental Theory of Calculus

Chapter 5: Elementary Functions and Some Typical Examples of Applications of Calculus

$\S 1$. Elementary Functions

$\S 2$. Typical Examples of Applications of Calculus 